\title{
Primordium Formation in Axenic Cultures of Agaricus bisporus (Lange) Sing.
}

\author{
By D. A. WOOD \\ Glasshouse Crops Research Institute, Rustington, Littlehampton, Sussex
}

(Received 9 December 1975)

\begin{abstract}
SUMMAR Y
Axenic cultures of some commercial strains of the cultivated mushroom, Agaricus bisporus, produced primordia on malt agar medium. The number of primordia differed both between strains, and within each strain when inoculated on to replicate plates. Primordium formation was also dependent on the agar source; it was repressed by changes in the $\mathrm{pH}$ of the medium and its constitution, including the addition of further carbohydrate sources; and required translocation from a nutrient source and the presence of an air-agar interface. Two strains grown on malt agar formed complete sporophores, but only at a very low frequency. Attempts to produce mature sporophores from the primordia by using supplementary nutrients were unsuccessful.

Primordium formation was not stimulated by live suspensions or culture filtrates of Pseudomonas putida, suspensions of other bacteria, iron salts, ironbinding compounds or other iron-containing compounds. Cyclic AMP, theophylline and caffeine also had no effect.
\end{abstract}

\section{INTRODUCTION}

Strains of the cultivated mushroom, Agaricus bisporus (Lange) Sing., usually fail to differentiate sporophore primordia on conventional fungal culture media. Couvy (1972), using a two-medium technique, suggested that a transition from rich to poor medium is a requirement for primordium formation. Under commercial conditions, fructification of A. bisporus is promoted by covering the mycelium-colonized compost with a layer of soil or peat-chalk mixture known as the casing layer. Eger (I96I) showed that this layer must contain a viable microbial flora for fruiting to occur. Hayes, Randle \& Last (I969) isolated bacteria from such casing layers which, when returned to sterile casing layers over axenically grown cultures of $A$. bisporus in compost, induced the production of fruit bodies. Hume \& Hayes (1972) claimed that these bacteria, which were identified as strains of Pseudomonas putida, could also stimulate $A$. bisporus strains to produce sporophore primordia in axenically grown plate cultures on malt extract medium. Culture filtrates of such bacteria produced a similar effect. Park \& Agnihotri (1969), using sterilized soil or soil extract agar to support axenic growth of $A$. bisporus, showed that a range of soil bacteria, or their culture filtrates obtained using $0.45 \mu \mathrm{m}$ membrane filters, would promote fruit body production. It has also been claimed that primordium formation is promoted by the use of chelating agents or iron-containing compounds added to axenically grown plate cultures of $A$. bisporus (Hayes, 1972). Hayes (1974) suggested that the $P$. putida strains might act by producing ironchelating compounds, capable of binding iron from the sequestering conditions of the alkaline casing layer. Although no claim has been made as to the chemical identity of such compounds, it seems likely that they would be analogous to the well-studied, naturally 
occurring, iron-binding compounds such as the sideramines or siderochromes (Neilands, 1974).

Uno \& Ishikawa (1973a,b) have shown that, for Coprinus macrorhizus Rea f. microsporus Hongo, intracellular production of cyclic AMP and its degrading enzyme cyclic AMP phosphodiesterase are closely linked to the initial events of fruiting. Matthews $\&$ Niederpruem (1972) have observed that cyclic AMP can accelerate primordium formation in cultures of Coprinus lagopus (sensu Buller) on glucose media.

The present work examined the capacity of commercial strains of $A$. bisporus to form primordia on malt agar under axenic conditions, and determined the effect of concentration, composition and quantity of the medium on primordium formation. The variability in primordium formation between strains and within a strain was also considered, as was the efficacy of live suspensions and culture filtrates of strains of $P$. putida and of other compounds thought to be capable of promoting primordium formation in axenic plate cultures of $A$. bisporus and other basidiomycetes.

\section{METHODS}

Organisms. Most strains of A. bisporus were of commercial origin. Two, referred to as A and B, corresponded to the strains F (fluffy) and S (strandy) described by Hayes (1972). All strains readily produced sporophores under commercial growing conditions. The $P$. putida isolates, obtained from the National Collection of Industrial Bacteria, Aberdeen, Scotland, were originally isolated by Hayes et al. (1969) who showed that they could promote fruit body production in axenically grown cultures of $A$. bisporus.

Media and culture. Malt agar contained (per litre) $20 \mathrm{~g}$ malt extract (Boots Pure Drug Co. Nottingham) and $15 \mathrm{~g}$ agar (Difco Bacto or Technical agar). The agar was melted and the $\mathrm{pH}$ adjusted to $7 \cdot 5$, using $0 . \mathrm{I} \mathrm{M}-\mathrm{NaOH}$, prior to autoclaving; the $\mathrm{pH}$ was again measured after autoclaving and before inoculation. Standard volume $(25 \mathrm{ml})$ plates were poured in $9 \mathrm{~cm}$ diam. Petri dishes using an Accuramatic filler and, after solidification, were inoculated with agar squares $(2 \times 2 \mathrm{~mm})$ cut from the outer $3 \mathrm{~cm}$ of a previously colonized plate. Incubation was at 20 or $25{ }^{\circ} \mathrm{C}$ at a relative humidity of 50 to $70 \%$.

Shake cultures of $P$. putida were grown in the basal medium of Skerman (I967) supplemented with ethanol or glucose, at $0 . \mathrm{I}$ or $\mathrm{I} \cdot 0 \%(\mathrm{w} / \mathrm{v})$, as the sole carbon source. Other bacteria were grown as shake cultures in nutrient broth (Oxoid). Culture filtrates were prepared by centrifuging ( $10000 \mathrm{~g}, \mathrm{I} 0 \mathrm{~min}$ ) followed by filtration of the supernatant through $0.2 \mu \mathrm{m}$ membrane filters. Solutions of test compounds were prepared at the appropriate concentration and filtered through similar membranes. Strains of $P$. putida were bioassayed for their ability to produce sideramines or siderochromes using the procedure described by Burnham \& Neilands (I960): the indicator organism Arthrobacter JG9 gives a halo of growth, when inoculated as a lawn around colonies of the organism under test, if sideramines or siderochromes are produced. Live suspensions of $\boldsymbol{P}$. putida, other bacteria or compounds were introduced either embedded within agar plugs (Hayes, 1972) or by direct surface inoculation. Agar plugs containing the test materials were cut as $6 \mathrm{~mm}$ diam. $\times 3 \mathrm{~mm}$ discs: four of these were placed at equidistant points around the circumference and $0.5 \mathrm{~cm}$ from the margin of 2 to 3-week-old cultures of $A$. bisporus growing on malt agar plates. In other tests, four drops $(0.05 \mathrm{ml}$ each) of test material were placed on the agar in a similar pattern. Concentrations of test compounds are given as those present in the agar plate containing A. bisporus mycelium.

Chemicals. Aureomycin was obtained from Cyanamid; 8-hydroxyquinoline, ethylenediaminetetra-acetic acid (EDTA), sodium-EDTA, ferrous sulphate, cytochrome $c$, theophyl- 
Table I. Primordium production in cultures of A. bisporus on malt agar

Primordia were counted on Io plates for each strain after 6 weeks incubation at $25{ }^{\circ} \mathrm{C}$.

Total primordia on 10 plates

Strain
A
B
D62 I
D72 I
S22
S53
D702
F497
S9
D49
VB735
D649

\begin{tabular}{cc} 
Bacto agar & \multicolumn{2}{c}{ Technical agar } \\
I2 (+ aggregates) & Numerous aggregates \\
I2 & 0 \\
I8 & 0 \\
34 & 2 \\
9 & 3 \\
I0 & 2 \\
2 & 0 \\
0 & 0 \\
0 & 0 \\
28 & 1 \\
I3 & 0 \\
25 & 3
\end{tabular}

line and caffeine from BDH; and iron-EDTA from Koch-Light. Ferritin was from Calbiochem; and haemoglobin, catalase, myoglobin, cyclic AMP and dibutyryl cyclic AMP from Sigma. Arthrobactin, ferrioxamin B, coprogen and fusigen were a gift from Dr $\mathbf{H}$. Diekemann, Tübingen, Germany. Albomycin and enterobactin were a gift of Professor $\mathbf{J}$. Neilands, Berkeley, California, U.S.A. Ferrimycin was a gift from Dr H. Bickel, CIBAGeigy, Basle, Switzerland.

\section{RESULTS}

Primordium formation on malt agar. A primordium was defined as a structure of greater than I mm diam., composed of a dense hyphal mesh, with a smooth surface and visibly distinct from knots and strands of hyphae. When commercial strains of $A$. bisporus were inoculated on to malt extract plates, complete colonization took 3 to 4 weeks at $25{ }^{\circ} \mathrm{C}$. Many of the strains then formed either primordia or areas of dense hyphal aggregation (Table I). No primordia were formed before complete colonization of the plate. The stranded type of growth characteristic of many strains of this organism is shown in Fig. I where several primordia are also visible. Primordium formation in such strains was usually associated with hyphal strands. Sections of these primordia examined under a light microscope showed no obvious differences from similar-sized primordia taken from commercial mushroom houses. No differentiation of the gill region was observed in the primordia.

Variability of primordium formation. The strains examined showed marked differences in their ability to form primordia (Table I), ranging from strains $\mathrm{F} 497$ and S9, which did not form any, to those such as D72I, D49, D649, which gave an average of 2.5 per plate. The primordium-forming ability of such strains was retained for two years despite repeated transfer, between experiments, of vegetative mycelium. The number of primordia formed by a strain depended on the agar source (Table I); there were always more on malt plates solidified with Bacto agar than with Technical agar. One exception was the fluffy strain A where growth on malt plates solidified with Technical agar produced dense regions of hyphal aggregates. Radial extension rates were the same on both agars for a given strain.

In addition to the variability between strains, primordium formation was not uniform between replicate plates of the same strain (Table 2). Some such replicate plates never produced primordia within the period of observation, as shown in Fig. 2 for strain A growing on Bacto malt agar. 


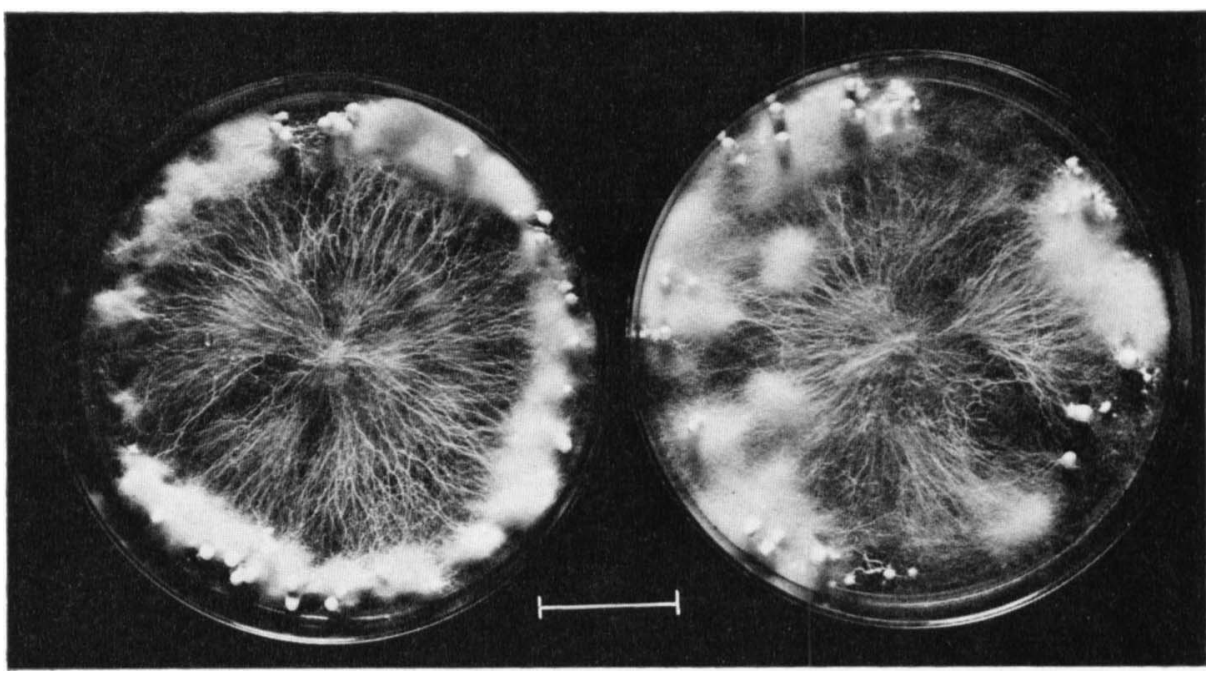

Fig. I. Mycelium and primordia of $A$. bisporus on malt agar plates. Bar marker represents $2 \mathrm{~cm}$.

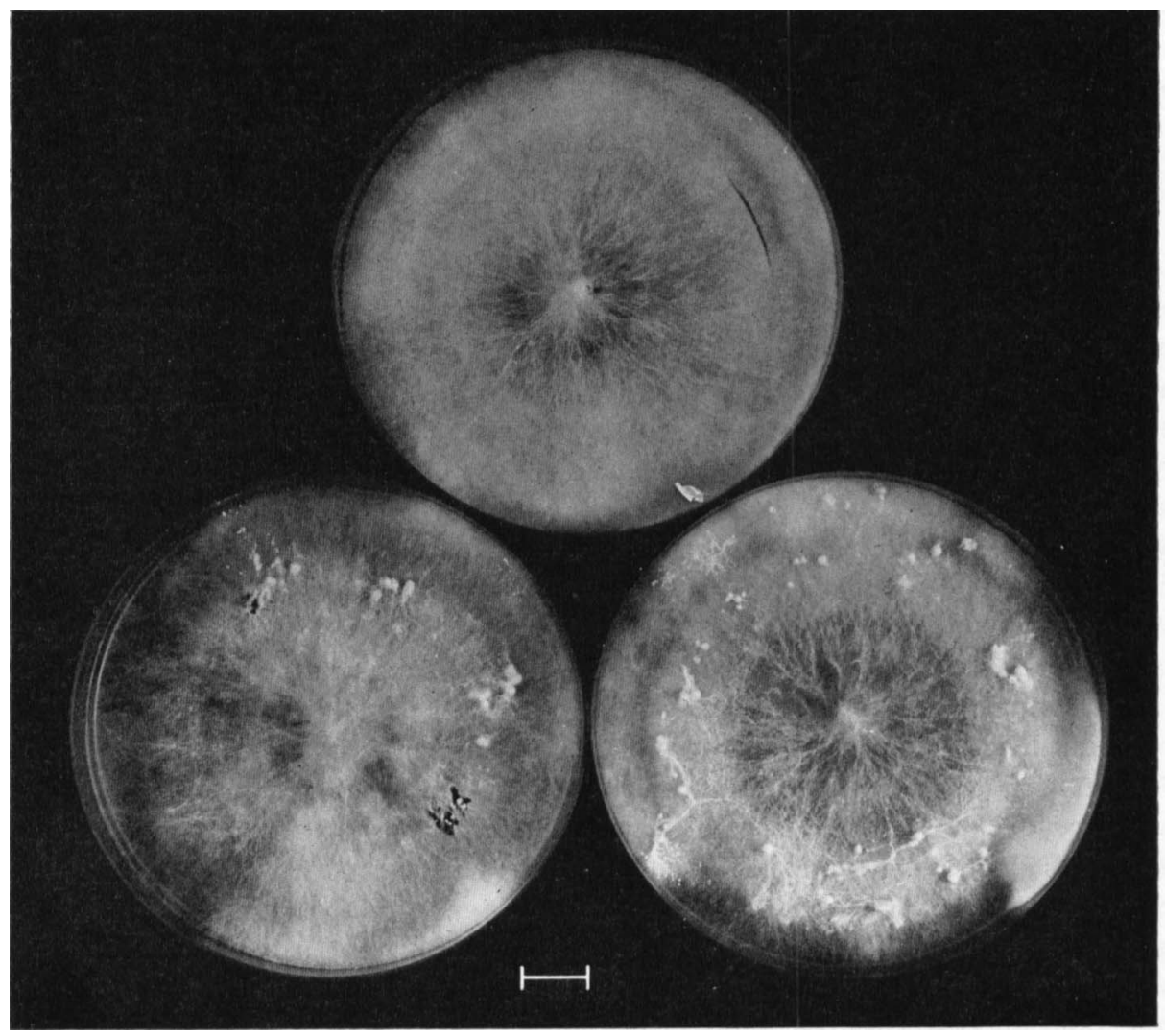

Fig. 2. Variability of primordium formation between replicate plates of strain A grown on Bacto malt agar. Bar marker represents $\mathrm{I} \mathrm{cm}$. 
Table 2. Numbers of primordia formed on 40 replicate plates each of strains A, B and D62I Cultures were incubated for 6 weeks at $25^{\circ} \mathrm{C}$.

No. of plates with:

$\begin{array}{lcccc}\text { Strain } & \text { No primordia } & \text { I primordium } & >\text { I primordium } & \text { Average per plate } \\ \text { A } & 5 & \text { I4 } & \text { 2I } & \text { I.4 } 4 \pm 0 \cdot 77 \\ \text { B } & 6 & 18 & 16 & \text { I.5 } \pm \text { I.07 } \\ \text { D62I } & \text { II } & 17 & 12 & 2 \cdot 1 \pm \mathrm{I} \cdot 85\end{array}$

Table 3. Effect of malt extract concentration on primordium formation

Primordia were counted on 10 plates for each strain after 6 weeks incubation at $25^{\circ} \mathrm{C}$.

\begin{tabular}{ccc}
$\begin{array}{c}\text { Concn of malt extract } \\
(\%, w / v)\end{array}$ & Total primordia on Io plates \\
\cline { 2 - 3 } 0.5 & Strain A & Strain D62I \\
I.0 & 0 & 0 \\
1.5 & 1 & 2 \\
$2 \cdot 0$ & 9 & 14 \\
2.5 & 10 & 20 \\
3.0 & 8 & 17 \\
4.0 & 2 & 5 \\
& 0 & 0
\end{tabular}

Table 4. Effect of initial $p H$ on the number of primordia formed by strains of $A$. bisporus grown on malt agar plates

$\begin{array}{ccc}\begin{array}{c}\text { Initial pH } \\ \text { of agar }\end{array} & \overbrace{\text { Strain D62I }}^{\text {Total primordia on io plates }} \\ 4.5 & 0 & \text { Strain B } \\ 5.0 & 0 & 0 \\ 5.5 & 0 & 0 \\ 6.0 & 1 & 2 \\ 6.5 & 3 & 3 \\ 7.0 & 13 & 8 \\ 7.5 & 21 & \text { II } \\ 8.0 & 16 & 14 \\ 8.5 & 7 & 12 \\ & 7 & 4\end{array}$

Effect of medium concentration and $p H$. Production of primordia was related to the concentration of malt extract in the medium, and was maximal on $2 \%(\mathrm{w} / \mathrm{v})$ malt extract (Table 3). At higher concentrations, the radial extension rate was very slow and the mycelium very dense, whilst at lower concentrations, the mycelium was very sparse.

The optimal $\mathrm{pH}$ range for primordium production was 7.0 to 8.0 (Table 4). In this context it is noteworthy that the $\mathrm{pH}$ of commercial mushroom composts is normally in the range 6.5 to 7.5 at the time of fruiting.

Effect of supplementation with carbohydrates. Although A. bisporus will utilize many of the common, naturally occurring sugars as sole carbon source (Treschow, 1944), the addition of certain of these to malt extract media repressed primordium formation. Preliminary experiments to examine the growth yield of mycelium were carried out on Treschow's (1944) basal medium supplemented with various sole carbon sources (Table 5). These carbon sources were then used as supplements in the malt extract medium, and the radial extension 
Table. 5 Growth yield of A. bisporus mycelium on Treschow's basal medium supplemented with various sole carbon sources

$\begin{array}{lc}\text { Carbon source } & \begin{array}{c}\text { Growth yield } \\ \text { (g dry wt mycelium/g carbon source) }\end{array} \\ \text { Glucose } & 0.30 \\ \text { Mannitol } & 0.28 \\ \text { Fructose } & 0.25 \\ \text { Xylose } & 0.23 \\ \text { Cellobiose } & 0.16 \\ \text { Galactose } & 0.13 \\ \text { Maltose } & 0.12 \\ \text { Arabinose } & 0.10 \\ \text { Sucrose } & 0.10\end{array}$

Table 6. Radial extension rate and primordium formation on malt extract media supplemented with various carbohydrates

Medium

Malt extract (ME)

$\mathrm{ME}+\mathrm{I} \%(\mathrm{w} / \mathrm{v})$ glucose

$\mathrm{ME}+2 \%(\mathrm{w} / \mathrm{v})$ glucose

$\mathrm{ME}+\mathrm{I} \%$ (w/v) mannitol

$\mathrm{ME}+\mathrm{I} \%(\mathrm{w} / \mathrm{v})$ fructose

$\mathrm{ME}+\mathrm{I} \%(\mathrm{w} / \mathrm{v})$ xylose

$\mathrm{ME}+\mathrm{I} \%(\mathrm{w} / \mathrm{v})$ cellobiose

$\mathrm{ME}+\mathrm{I} \%(\mathrm{w} / \mathrm{v})$ galactose

$\mathrm{ME}+\mathrm{I} \%(\mathrm{w} / \mathrm{v})$ maltose

$\mathrm{ME}+\mathrm{r} \%(\mathrm{w} / \mathrm{v})$ arabinose

$M E+I \%$ (w/v) sucrose
Radial extension rate (mm diam./day)

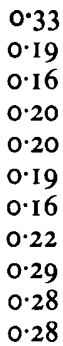

Total primordia on 10 plates

Table 7. Effect of reduction of colony size in the nutrient compartment of divided plates on subsequent primordium formation

Primordia were counted on Io replicate plates for each treatment after 6 weeks incubation at $25^{\circ} \mathrm{C}$.

Percentage of nutrient compartment removed

Total primordia on to plates

0
25
50
75
90

$\begin{array}{cc}\text { Strain D62 I } & \text { Strain B } \\ 23 & \text { I I } \\ \text { I9 } & 8 \\ 4 & \text { I } \\ \text { I } & 0 \\ \text { O } & 0\end{array}$

rate and primordium formation were recorded. The results (Table 6) indicate that the addition of carbon sources such as glucose or fructose repressed both the radial extension rate and primordium formation, whereas carbon sources such as arabinose and maltose had only small effects on these properties.

Requirement for a nutrient source for primordium formation. The quantity of primordia formed in other basidiomycete fungi usually depends on the mass of the supporting mycelium (Burnett, 1968). Whether or not such a dependence existed in A. bisporus strains was examined in the following manner. Several strains were grown on plates divided into two 
compartments: one contained malt agar, and the other water agar. When strains of A. bisporus were inoculated on to the nutrient side, the mycelium colonized that side completely and subsequently grew on to the water agar side. In certain strains, e.g. D62I and B, most ( $>95 \%$ ) of the primordia were formed on the water agar side at a frequency similar to that observed on single compartment plates; thus primordium formation could occur on a nonnutrient medium. In a further experiment, strains D62I and в were each inoculated separately on to 50 divided plates. After complete colonization of the malt agar side and approximately $50 \%$ colonization of the water agar side, sections of the nutrient half of the plates were removed. These corresponded to $25,50,75$ and $90 \%$ of the original malt agar volume. Six weeks after inoculation, the numbers of primordia were recorded (Table 7). The results indicated that the number formed depended on the size of the mycelium available in the nutrient part of the colony, but did not indicate the location of the materials necessary for their construction, i.e. whether there were internal or external to the supporting mycelium.

Requirement for an interface for primordium formation. Many examples are known where the formation of a fungal fruiting structure requires an air-solid or air-liquid interface (Morton, 1967; Smith \& Galbraith, 1971). This has been construed as evidence for a requirement for both submerged (hydrophilic) and surface (hydrophobic) types of mycelium for fruiting. To examine such a requirement for primordium formation in A. bisporus, several strains were inoculated on to malt agar plates which were then covered with washed, sterile, cellulose-acetate (Cellophane) film. Other plates were prepared in which cellulose-acetate film was placed on the agar surface, and the mycelial inoculum on the film. In both cases, the mycelium completely colonized the plates but no primordia were formed, except in the control plates where there were no cellulose-acetate discs. Similar results were obtained when sterile glass-fibre discs were used in place of the Cellophane.

Inhibition of primordium formation by carbon dioxide. Initiation of fruiting of $A$. bisporus in commercial growing chambers is partly controlled by ambient carbon dioxide levels (Tschierpe \& Sinden, 1964): levels above $0.1 \%$ are known to inhibit primordium formation. Strains inoculated on to malt agar plates failed to form primordia when grown on plates placed in incubators with no internal air circulation or when placed in sealed polythene bags. The radial extension rate was the same, or slightly greater, than on control plates incubated in constant temperature rooms, but the latter always formed primordia. Primordium formation was restored to cultures grown under conditions of limited air supply if the air supply had been passed through I $\mathrm{M}-\mathrm{KOH}$.

Since increased carbon dioxide levels inhibited primordium formation in axenic conditions, the possibility was examined that variability between colonies on replicate plates might be caused by differences in the concentration of carbon dioxide. Accordingly, a series of plates was inoculated and primordia allowed to form. The carbon dioxide levels of plates of similar age of mycelium with and without primordia were then examined by gas chromatography. No significant differences were detected.

Attempts to promote primordium enlargement. In almost all experiments primordia failed to develop beyond a diameter of $\mathrm{I}$ to $2 \mathrm{~mm}$. Malt extract has a carbohydrate content of $90 \%$ and a nitrogen content of 4 to $5 \%$ (Bridson \& Brecker, 1970), equivalent to $0.36 \mathrm{~g}$ carbon and $0.02 \mathrm{~g}$ nitrogen per $20 \mathrm{ml}$ malt agar medium on a single plate. Mycelial yields of approximately $0.09 \mathrm{~g}$ dry weight were obtained from each plate; this might be sufficient to support development of one small sporophore (Madelin, 1956). However since mature sporophores formed only rarely, experiments were carried out to see whether possible nutrient limitation might be overcome to allow mature sporophores to develop from the primordia. Three types of experiments were carried out: (i) transfer of agar discs bearing mycelium to 
Table 8. Effect of Pseudomonas putida isolates on primordium formation

\begin{tabular}{|c|c|c|c|c|}
\hline \multirow{2}{*}{ Treatment } & \multicolumn{4}{|c|}{ Total primordia on to plates } \\
\hline & \multirow{2}{*}{$\begin{array}{c}\text { Strain A } \\
\text { I4 }\end{array}$} & \multirow{2}{*}{$\begin{array}{c}\text { Strain B } \\
\text { I4 }\end{array}$} & \multicolumn{2}{|c|}{ Strain D621 Strain S22 } \\
\hline Control & & & 16 & 10 \\
\hline Culture medium only & 12 & I6 & 20 & 8 \\
\hline \multicolumn{5}{|l|}{$P$. putida isolates } \\
\hline I & IO & I6 & I4 & 8 \\
\hline 2 & I6 & 10 & 15 & 7 \\
\hline 3 & 17 & 9 & I I & 12 \\
\hline 4 & 8 & I 8 & I6 & I I \\
\hline 5 & 12 & I 7 & 17 & IO \\
\hline 6 & I4 & I I & 13 & 8 \\
\hline 7 & IO & 17 & I7 & 7 \\
\hline 8 & I5 & I3 & 15 & 9 \\
\hline
\end{tabular}

various fresh media; (ii) injection of primordia with carbon sources such as glucose, fructose and mannitol; (iii) excision of competing primordia leaving only a single primordium per plate. In no case was any development of primordia observed.

Development of complete sporophores. Although attempts to influence the development of primordia were unsuccessful, two strains (B, D62I) occasionally formed complete sporophores following growth on malt agar plates. The frequency of this event was about one complete sporophore per 1000 plates inoculated per strain. The sporophores formed were small but normal, as judged by their overall morphology. In addition they formed spores which were able to germinate. No evidence was obtained that other contaminating microorganisms were present on the plates on which the sporophores had developed.

Effects of Pseudomonas putida strains and other bacteria on primordium formation. Tests with live suspensions of eight strains of $P$. putida either embedded in agar plugs or as direct surface inoculations were made with four strains of $A$. bisporus (A, B, D621, S22) growing on malt agar medium. Strains A and B were those previously examined for primordium formation (Hume \& Hayes, 1972). There was no increase in the number of primordia over those on untreated control plates (Table 8). Samples of culture filtrates from the $P$. putida isolates, obtained after one or two weeks growth in Skerman's (1967) basal medium with ethanol or glucose as sole carbon source, also had no effect on primordium formation. Hayes (1974) suggested that such $P$. putida strains might act by producing iron-binding compounds. Iron limitation of microbial cultures is known to derepress the formation of such compounds (Neilands, 1974). Therefore two strains of $P$. putida were grown in Skerman's basal medium containing $\mathrm{I} \%(\mathrm{w} / \mathrm{v})$ ethanol and iron concentrations of $0,0.03,0.15,0.3$ and $0.9 \mu \mathrm{g} \mathrm{ml}^{-1}$. Culture filtrates taken after two weeks growth failed to stimulate significantly the formation of primordia. Nevertheless the $P$. putida strains were capable of sideramine or siderochrome production, as determined by their ability to promote growth of Arthrobacter JG9 in bioassays. Other live suspensions of bacteria known to produce one or more of these ironbinding compounds, namely Salmonella typhimurium LT2, Aerobacter aerogenes and Bacillus subtilis (Neilands, 1974), were also examined. None had any apparent effect on primordium formation in malt agar plates.

Effect of chelating compounds and iron-containing compounds. A series of chelating or ironcontaining compounds were tested against three strains of $A$. bisporus (A, B, D62I) for their ability to promote primordium formation. Aureomycin, 8-hydroxyquinoline, ethylenediaminetetra-acetic acid (EDTA), iron-EDTA, sodium-EDTA, ferric sulphate, haemoglobin, 
ferritin, catalase, cytochrome $c$ and myoglobin were tested at $0.2,2,20,200 \mu \mathrm{g} \mathrm{ml}^{-1}$. The microbially-produced iron-binding compounds, fusigen, coprogen, enterobactin, arthrobactin, ferrimycin, ferrioxamin B and albomycin were tested at $0 \cdot 2,2$ and $10 \mu \mathrm{g} \mathrm{ml}^{-1}$. None of these compounds stimulated the production of primordia in axenic plate cultures of A. bisporus.

Effect of cyclic AMP and phosphodiesterase inhibitors. Cyclic AMP and dibutyryl cyclic AMP at $0 \cdot \mathrm{I}, \mathrm{I}, 5$ and $10 \mu \mathrm{g} \mathrm{ml}^{-1}$, and theophylline and caffeine at $0 \cdot 2,2,20$ and $200 \mu \mathrm{g} \mathrm{ml}^{-1}$, had no effect on primordium formation. The highest concentrations of theophylline and caffeine slightly inhibited growth.

\section{DISCUSSION}

The results presented here show that many $A$. bisporus strains produce primordia in axenic conditions on a complex medium such as malt extract. All the strains examined formed primordia on a single medium; and so, it should be possible to examine more precisely the nutritional requirements for primordium formation.

Primordium formation in these strains of $A$. bisporus occurred after the cessation of vegetative growth, whereas in Schizophyllum commune, primordium initials are formed during colony growth (Wessels, I965). Commercial agars differ considerably in composition (Bridson \& Brecker, 1970), particularly with respect to metal ions. The differences in primordium forming ability on the two agars indicate that this may be more sensitive than vegetative growth to ionic or organic impurities in the agar. The compounds responsible for these differences are not yet known, but it is of interest that the radial extension rate is not affected whereas fructification is. Formation of fruiting structures in fungi is often more nutritionally exacting than is vegetative growth (Hawker, 1966).

The factors determining variability in primordium formation between replicate plates are not evident and suggest that the cultural conditions were at a threshold of some variable not yet under control. Primordium formation seemed to be partly affected by the radial extension rate of the mycelium. The observation that certain carbohydrates added to malt agar repress primordium formation but are nevertheless good growth substrates (Tables 5, 6) may indicate that primordium formation is regulated by a process similar to catabolite repression. Similar observations concerning the relationships of vegetative growth and fruiting have been made with Schizophyllum commune and Coprinus macrorhizus (Schwalb, I97I ; Uno \& Ishikawa, 1974).

The level of primordium formation is partly determined by the size of the vegetative mycelium from which it develops (Table 7) and it also depends on translocation from the mycelium, as observed for other basidiomycete fruiting bodies (Madelin, 1956; Burnett, 1968). The extent of the contribution of medium and mycelium to primordium formation remains to be investigated.

Axenically grown cultures in high ambient carbon dioxide levels failed to produce primordia. The inhibitory effect of high carbon dioxide concentrations has also been observed in commercial growing procedures for $A$. bisporus and for fructification of other basidiomycetes (Taber, 1966).

The reasons for the failure of most axenically grown primordia to develop further remain obscure. Evidence from the nutritional and biochemical requirements of sporophore development in other basidiomycetes (Wessels, 1965; Wessels \& Niederpruem, 1967) indicates that both the quantity and the composition of the vegetative mycelium is critical in regulating the number of primordia formed and their subsequent development. In S. commune, sporophore development occurs in the absence of a utilizable carbon source and can be inhibited by 
high glucose levels in the medium (Wessels, I965; Wessels \& Niederpruem, 1967). Experiments designed to promote primordium formation by addition of exogenous nutrients to axenic cultures of $A$. bisporus might therefore repress any further development of primordia. Development of a chemically-defined medium that promotes primordium formation would greatly assist these studies.

No evidence was obtained to suggest that $P$. putida strains act on primordium formation through the production of iron-binding metabolites (Hayes, 1974) although these strains can produce such compounds (Neilands, 1974). Neither chelating agents nor any of the other iron compounds tested had any detectable effect. The fact that changes in agar caused differences in primordium formation might indicate that the reason why chelating agents have previously been observed to stimulate primordium formation was that these agents bound toxic metal ion(s) present in the agar.

Fructification of $A$. bisporus can be induced in axenic cultures grown in compost by casing with layers of sterile activated charcoal (Eger, I96I ; Long \& Jacobs, 1974). Long \& Jacobs' (1974) experiments on axenic fruiting of $A$. bisporus showed that any compound involved in fruiting initiation must be of low volatility. Their work and the observations presented here indicate that the role of the casing microflora is more likely to be the removal of one or more self-inhibitors of fruiting than a positive contribution of fruit-inducing substances. Selfinhibitors have been identified as regulators of fungal spore germination (Macko et al., I97I), but have not yet been clearly shown in fruiting of basidiomycetes. The production of one or more such compounds by $A$. bisporus mycelium to control primordium formation is currently under investigation.

I thank Dr D. M. Spencer, Dr D. Price and Mr T. J. Elliott for their helpful comments on this work. The technical assistance of Mr S. Matcham is gratefully acknowledged. The carbon dioxide determinations were performed by $\mathrm{Mr}$ J. Hammond of this Institute.

\section{REFERENCES}

Bridson, E. Y. \& Brecker, A. (1970). Design and formulation of microbial culture media. In Methods in Microbiology, vol. 3A, pp. 229-295. Edited by J. R. Norris and D. W. Ribbons. London and New York: Academic.

Burnett, J. H. (1968). Fundamentals of Mycology. London: Edward Arnold.

Burnham, B. F. \& NeilandS, J. B. (1960). Studies on the metabolic function of the ferrichrome compounds. Journal of Biological Chemistry 236, 554-559.

Couvy, J. (1972). Etude de l'induction de la fructification chez Agaricus bisporus (Lange) Sing. (= Psalliota hortensis $\mathrm{Cke})$ : action du glucose. Comptes rendus hebdomadaire des séances de l'Académie des sciences 274, 2475-2477.

EGER, A. (196I). Untersuchungen über die Funktion der Deckschicht bei der Fruchtkörperbildung des Kulturchampignons, Psalliota bispora Lg. Archiv für Mikrobiologie 39, 313-334.

HAWKer, L. (1966). Environmental influences on reproduction. In The Fungi, vol. II, pp. 435-469. Edited by G. C. Ainsworth and A. S. Sussman. New York and London: Academic.

HAYES, W. A. (1972). Nutritional factors in relation to mushroom production. In Mushroom Science, vol. 8, pp. 663-674. Edited by R. L. Edwards. London: Mushroom Growers Association.

HAYES, W. A. (I974). Microbiological activity in the casing layer and its relation to productivity and disease control. In The Casing Layer, pp. 27-48. Edited by W. A. Hayes. London: Mushroom Growers Association.

Hayes, W. A., Randle, P., E. \& Last, F. T. (1969). The nature of the microbial stimulus affecting sporophore formation in Agaricus bisporus (Lange) Sing. Annals of Applied Biology 64, 177-187.

Hume, D. P. \& HAYES, W. A. (1972). The production of fruit-body primordia in Agaricus bisporus (Lange) Sing. on agar media. In Mushroom Science, vol. 8, pp. 527-532. Edited by R. L. Edwards. London: Mushroom Growers Association.

LONG, P. E. \& JACOBS, L. (1974). Aseptic fruiting of the cultivated mushroom, Agaricus bisporus. Transactions of the British Mycological Society 63, 99-107. 
Macko, V., Staples, R. C., Allen, P. J. \& Renwick, J. A. A. (I97I). Identification of the germination selfinhibitor from wheat stem rust uredospore. Science, New York r73, 835-836.

Madelin, M. F. (I956). Studies on the nutrition of Coprinus lagopus Fr., especially as affecting fruiting. Annals of Botany 20, 307-330.

Matthews, R. R. \& Niederpruem, D. J. (1972). Differentiation in Coprinus lagopus. I. Control of fruiting and cytology of initial events. Archiv für Mikrobiologie 87, 257-268.

Morton, A. G. (1967). Morphogenesis in fungi. Science Progress, Oxford 55, 597-6I I.

NeIlands, J. B. (1974). Microbial Iron Metabolism. New York: Academic.

Park, J. V. \& Agnihotri, V. P. (1969). Bacterial metabolites trigger sporophore formation in Agaricus bisporus. Nature, London 222, 984.

SCHWALB, M. N. (197I). Commitment to fruiting in synchronously developing cultures of the basidiomycete Schizophyllum commune. Archiv für Mikrobiologie 79, 102-107.

SKerman, V. B. D. (1967). A Guide to the Identification of the Genera of Bacteria. Baltimore, U.S.A.: Williams and Wilkins.

Smith, J. E. \& Galbraith, J. C. (I97I). Biochemical and physiological aspects of differentiation in the fungi. Advances in Microbial Physiology 5, 45-I 34 .

Taber, W. A. (1966). Morphogenesis in Basidiomycetes. In The Fungi, vol. II, pp. 387-4I2. Edited by G. C. Ainsworth and A. S. Sussman. New York and London: Academic.

Treschow, C. (I944). Nutrition of the cultivated mushroom. Dansk botanisk Arkiv II, I-I 80.

TSCHIERPE, H. J. \& Sinden, J. S. (1964). Weitere Untersuchungen über die Bedeutung von Kohlendioxyd für die Fruktifikation des Kulturchampignon Agaricus campestris, var. bisporus (L) Lge. Archiv für Mikrobiologie 49, 405-425.

Wessels, J. G. H. (1965). Morphogenesis and biochemical processes in Schizophyllum commune Fr. Wentia I3, I-II3.

WesSELS, J. G. H. \& Niederpruem, D. J. (1967). Role of a cell-wall glucan-degrading enzyme in matings of Schizophyllum commune. Journal of Bacteriology 94, 1 594-1602.

Uno, I. \& Ishikawa. T. (I973a). Purification and identification of the fruit-inducing substances in Coprinus macrorhizus. Journal of Bacteriology $113,1240-1248$.

UNo, I. \& Ishikawa, T. (I973 $b$ ). Metabolism of adenosine $3^{\prime}, 5^{\prime}$-cyclic monophosphate and induction of fruiting bodies in Coprinus macrorhizus. Journal of Bacteriology 113, 1249-1 255.

UNo, I. \& IsHIKAWA, T. (1974). Effect of glucose on the fruiting body formation and adenosine $3^{\prime}, 5^{\prime}$-cyclic monophosphate levels in Coprinus macrorhizus. Journal of Bacteriology 120, 96-100. 